\title{
Estimated Quality-Adjusted Life-Year Associated with the Degree of Activities of Daily Living in Patients with Alzheimer's Disease
}

\author{
Mari Kasai Kenichi Meguro \\ Department of Geriatric Behavioral Neurology, Tohoku University Graduate School of Medicine, \\ Sendai, Japan
}

Key Words

Quality-adjusted life-year · Activities of daily living · Alzheimer's disease

\begin{abstract}
Background/Aims: The quality-adjusted life-year (QALY) and health state utility values (HSUVs) are major quality of life scales that are used for the analyses of health economics of diseases such as Alzheimer's disease (AD). In Japan, the most common dementia disease is AD with cerebrovascular diseases (CVD), followed by 'pure' $A D$. There is a need to reconsider QALY and HSUVs in the context of activities of daily living (ADL) levels in AD and AD with CVD. Methods: Studies on QALY and HSUVs based on ADL levels in AD were identified using a PubMed search. HSUVs were estimated in AD patients with ADL levels $A$ (independent walking and eating), B (some problems with walking but sitting without assistance), and C (confined to bed). These three ADL levels correspond approximately to the stages of Mobility on the EQ5D. Results: There has been no previous report on HSUVs related to the level of physical activity of patients with AD. From the previous reports and EQ-5D, we estimated that the HSUVs of pure AD and AD with CVD for ADL levels $A, B$, and $C$ were 0.61 and $0.58,0.53$ and 0.28 , and 0.19 and 0.05 , respectively. Conclusion: Effects of ADL should be considered during the decision making process in health policy for dementia care in Japan. $\odot 2013$ S. Karger AG, Basel
\end{abstract}

\section{Introduction}

The prevalence of dementia has been found to be $8.5 \%$ in a population aged $\geq 65$ years in a cohort study in Tajiri [1] and $12.4 \%$ in a population aged $\geq 75$ years in a cohort study in Kurihara [2]. The estimated prevalence of dementia in subjects aged $\geq 75$ years with an impairment level of dementia in the Long-Term Care Insurance system is $23.6 \%$ [2]. Thus, 
there were an increasing number of elderly patients with dementia. However, medical resources are limited, and there is a need to identify the most effective treatment options among approaches with similar costs [3]. This has increased the importance of the analysis of the economic effects of dementia during the decision making process in healthcare policy.

The health state utility values (HSUVs) and quality-adjusted life-year (QALY) are used as indicators in the economic analysis of dementia [4]. The HSUVs are an interval scale in which health-related quality of life is scored as 0 for death and 1 for complete health [4]. In the economic evaluation of healthcare, cost-effectiveness is analyzed by estimating an incremental cost-effectiveness ratio using the HSUVs. The QALY is a total indicator combining health-related quality of life and survival benefit, that is, the HSUVs multiplied by lifetime under the relevant conditions. For example, if the HSUVs of cerebrovascular disease (CVD) are 0.60 and the lifetime for CVD is 10 years, QALY is $0.60 \times 10=6$. Therefore, the analysis of healthcare economics requires an estimation of the HSUVs based on the disease and injury levels.

Alzheimer's disease (AD) is the most common type of dementia. In Japan, the percentage of cases of AD with CVD is approximately double that of AD without CVD (i.e., 'pure' AD), with these cases accounting for 43.8 and $18.8 \%$, respectively, of all dementia cases [1]. Many patients with $\mathrm{AD}$ associated with CVD also have impaired activities of daily living (ADL) due to low physical activity, in addition to the effects of AD; thus, these patients may be admitted to nursing facilities or require more long-term care. Evaluation of the effects of pharmacotherapy including antidementia drugs requires the estimation of the HSUVs based on the extent of impaired ADL and the outcomes of AD. The objective of this study was to estimate the HSUVs in AD with the inclusion of ADL.

\section{Methods}

\section{Literature Search}

International articles were searched for using PubMed (MEDLINE). The date of the search was July 9, 2013. The search keywords (with variants in parentheses) were 'qaly (qalys)', 'activities of daily living (ADL)', and 'Alzheimer (Alzheimer's)'. Articles were also searched for by replacing 'qalys' with 'HSUVs' or 'EQ-5D', and 'Alzheimer' with 'stroke', 'aphasia' or 'Parkinson's disease'.

Domestic articles were searched for in the Japan Medical Abstract Society Web version 5. The date of the search was also July 9, 2013. The keywords were 'health state utility values', 'dementia' and 'activities of daily living (ADL)'.

\section{Estimation of the HSUVS}

\section{Pure AD}

The EQ-5D [5-7] is frequently used in international articles, particularly because the EQ-5D score for mobility is consistent with the A, B, and C levels of the 'independence in daily activities' scale used in the Long-Term Care Insurance system (ADL care levels). ADL level A indicated that patients could independently walk and eat. ADL level B showed that patients had some problems in walking but could sit without assistance. ADL level C meant confined to bed [8]. The EQ-5D scores for mobility consist of three levels: (1) 'no problems walking around', (2) 'some difficulties walking around', and (3) 'confined to bed'. Thus, the ADL levels of the Japanese Long-Term Care Insurance approximately correspond to each stage of Mobility of the EQ-5D. 
Table 1. ADL-related HSUVs using EQ-5D in international articles: AD

\begin{tabular}{|c|c|c|c|}
\hline \multicolumn{3}{|l|}{ Reviewed papers } & \multirow[t]{2}{*}{ Our comments } \\
\hline first author & patients & HSUVs & \\
\hline $\begin{array}{l}\text { Shearer [10], } 2012 \\
(12 \text { articles, } \mathrm{n}=2,998)\end{array}$ & $\mathrm{AD}$ & $\begin{array}{l}\text { mild }=0.52-0.73, \text { moderate }=0.30 \\
-0.53, \text { severe }=0.12-0.49\end{array}$ & $\begin{array}{l}\text { systematic review; no } \\
\text { description of ADL levels }\end{array}$ \\
\hline $\begin{array}{l}\text { Jönsson [11], } 2005 \\
(\mathrm{n}=225)\end{array}$ & $\mathrm{AD}$ & $\begin{array}{l}\text { independent }=0.65 \text {, dependent }= \\
0.32\end{array}$ & $\begin{array}{l}\text { estimated values based on the } \\
\text { previous study }\end{array}$ \\
\hline $\begin{array}{l}\text { Andersen [12], } 2004 \\
(n=244)\end{array}$ & $\begin{array}{l}\text { AD 67\%, } \\
\operatorname{VaD} 33 \%\end{array}$ & $\begin{array}{l}\text { mild }=0.636, \text { moderate }=0.596 \\
\text { severe }=0.486 ; \text { independent }= \\
0.641, \text { dependent }=0.343 ; \\
\text { community }=0.621, \text { institution }= \\
0.564\end{array}$ & $\begin{array}{l}\text { values of all causative diseases } \\
\text { of dementia }\end{array}$ \\
\hline
\end{tabular}

$\mathrm{VaD}=$ Vascular dementia

We postulated that, in pure $\mathrm{AD}$, the severity of cognitive dysfunction directly relates to the degree of ADL disability. We used ADL levels to estimate the HSUVs which took into consideration the severity of AD, ADL disability, and cognitive impairment [5-7].

AD with CVD

In $\mathrm{AD}$ with CVD, the low level of ADL may be affected by physical dysfunction, such as hemiplegia as well as cognitive deficits. In the previous study, the care level of the Japanese Long-Term Care Insurance had a good correlation with the Barthel index [9]. We reanalyzed the data of the long-term care level of the Kurihara Project for calculating the estimated HSUVs in AD with CVD [2]. The old-old population aged 75 years and older to whom the LongTerm Care Insurance index applied in Kurihara (135 subjects had ADL level A, 43 subjects had ADL level B, and 34 subjects had ADL level C) was analyzed using the $\chi^{2}$ test [2].

\section{Results}

\section{Literature Search}

International Research

A literature search of international articles using the keywords 'qaly (or qalys)', 'activities of daily living (or ADL)' and 'Alzheimer (or Alzheimer's)' identified 10 articles. Replacing 'qaly' with 'EQ-5D' also resulted in 10 articles, and replacing 'qaly' with 'HSUVs' resulted in 8 articles. However, there were no descriptions of HSUVs associated with the degree of ADL levels in the previous reports. International studies on AD and ADL-related HSUVs using EQ-5D are shown in table 1 [10-12]. Table 1 summarized the previous HSUV reports of AD using EQ-5D except for drug treatment. The study of Shearer et al. [10] is a systematic review and does not describe the extent of ADL, but clearly showed HSUVs based on the severity of AD: $0.52-0.73$ in mild AD, $0.30-0.53$ in moderate $A D$, and $0.12-0.49$ in severe AD. The other articles $[11,12]$ found HSUVs of $0.64-0.65$ for AD with independent ADL and $0.32-0.34$ for AD with dependent ADL.

Table 2 shows the previous HSUV papers of stroke/stroke and aphasia/Parkinson's disease with dementia. Tengs and Lin [13] reported that the HSUVs in minor stroke equal to 
Table 2. ADL-related HSUVs using EQ-5D in international articles: stroke/stroke and aphasia/PD with dementia

\begin{tabular}{llll}
\hline Reviewed papers & & \multirow{2}{*}{ Our comments } \\
\cline { 1 - 2 } first author & patients & HSUVs & \\
\hline $\begin{array}{llll}\text { Tengs [13], 2003 } \\
(20 \text { articles) }\end{array}$ & stroke & $\begin{array}{l}\text { minor stroke }=0.87, \\
\text { moderate stroke }=0.68, \\
\text { major stroke }=0.52\end{array}$ & $\begin{array}{l}\text { meta-analysis; no } \\
\text { description of cognitive } \\
\text { impairment and dementia }\end{array}$ \\
\hline $\begin{array}{llll}\text { van der Gaag [14], 2008 } \\
(\mathrm{n}=17)\end{array}$ & stroke and aphasia & stroke and aphasia $=0.31$ & $\begin{array}{l}\text { no description of severity } \\
\text { of disorders }\end{array}$ \\
\hline $\begin{array}{l}\text { Johnson [15], 2013 } \\
(10 \text { articles, } n=3,318)\end{array}$ & PD & PD with dementia $=0.20$ & $\begin{array}{l}\text { regardless of Hoehn and } \\
\text { Yahr stage }\end{array}$ \\
\hline
\end{tabular}

$\mathrm{PD}=$ Parkinson's disease

Table 3. ADL-related HSUVs using EQ-5D in Japanese articles

\begin{tabular}{|c|c|c|c|}
\hline \multicolumn{3}{|l|}{ Reviewed papers } & \multirow[t]{2}{*}{ Our comments } \\
\hline first author & patients & HSUVs & \\
\hline $\begin{array}{l}\text { Yasuda [16], } 2011 \\
(\mathrm{n}=107)\end{array}$ & $\begin{array}{l}\mathrm{AD} \\
(\text { mean } \mathrm{MMSE}=18.4)\end{array}$ & mean value $=0.66$ & $\begin{array}{l}\text { no HSUVs based on severity } \\
\text { or ADL ability }\end{array}$ \\
\hline $\begin{array}{l}\text { Kurimori [17], } 2010 \\
(\mathrm{n}=2,593)\end{array}$ & $\begin{array}{l}\text { requiring long-term } \\
\text { care }\end{array}$ & $\begin{array}{l}\text { long-term care: care level } 1= \\
0.61, \text { care level } 2=0.54, \text { care } \\
\text { level } 3=0.45, \text { care level } 4= \\
0.11, \text { care level } 5=-0.01\end{array}$ & $\begin{array}{l}\text { no description of diagnosis } \\
\text { of dementia and ADL-related } \\
\text { independence levels }\end{array}$ \\
\hline $\begin{array}{l}\text { Izumi [18], } 2010 \\
(n=140)\end{array}$ & CVD, etc. & $\mathrm{CVD}=0.53$ & $\begin{array}{l}\text { presence/absence of } \\
\text { cognitive dysfunction was } \\
\text { not evaluated }\end{array}$ \\
\hline
\end{tabular}

0.87 , in moderate stroke 0.68 , and in major stroke 0.52 when using meta-analysis, but no description of cognitive impairment and dementia. The HSUVs in stroke and aphasia equal to 0.31 , but there was no description of the severity of the disorders in this paper [14]. Johnson et al. [15] described that the HSUVs in Parkinson's disease with dementia equal to 0.20. There was no description on HSUVs associated with low ADL levels in stroke with dementia or vascular dementia in the previous reports.

Domestic Research

ADL-related HSUVs using EQ-5D in domestic studies are summarized in table 3. Studies on $\mathrm{AD}$ [16], AD with long-term care [17] and the extent of ADL [18] were found, but none of these articles evaluated all of these issues together. Table 3 shows the previous HSUV reports of AD, ADL or CVD-related HSUVs in Japan. In Japan, however, there was no description of HSUVs associated with both ADL levels and AD. 


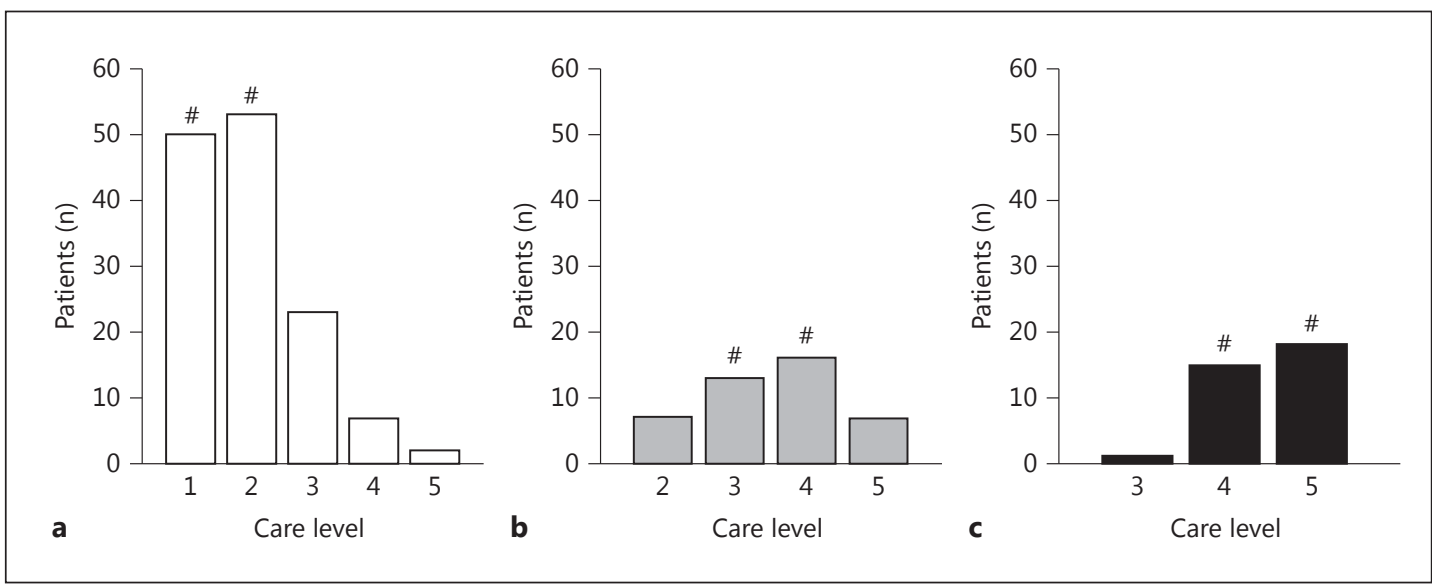

Fig. 1. Reanalysis of data of the Kurihara Project: long-term care level. a ADL-A ( $n=135)$. The first and second levels: Care Level 2 and 1 (\#) of Long-Term Care Insurance (\#). b ADL-B ( $\mathrm{n}=43)$. The first and second levels: Care Level 4 and 3 (\#). c ADL-C ( $\mathrm{n}=34)$. The first and second levels: Care Level 5 and 4 (\#).

\section{Estimation of HSUVS}

Pure AD

HSUVs were estimated based on ADL. The remaining items except for 'locomotion' on EQ-5D were supposed to be 2, and the levels of ADL-A, B, and C were accounted for 1, 2, and 3 , respectively [4]. The HSUVs were $0.61(12,222)$ [95\% confidence interval (CI) 0.804 (11,211)-0.494 (12,232)], 0.53 (22,222) [CI 0.676 (22,211)-0.280 (22,333)], and 0.19 $(32,222)$ [CI $0.332(33,311)-0.111(33,333)]$ for ADL levels A, B, and C, respectively.

\section{AD with CVD}

We calculated HSUVs in AD with CVD reanalyzing the data of the long-term care level of the Kurihara Project. Figure 1 shows the data of the Long-Term Care Insurance of the Kurihara Project. Figure 1 a shows the ADL-A $(n=135)$, figure $1 \mathrm{~b}$ shows the ADL-B $(n=43)$, and figure $1 \mathrm{c}$ shows the ADL-C $(n=34)$. We used the first and second levels of each the ADL group for the calculation of HSUVs. The first and second levels of the ADL-A are Care Level 2 and 1 of Long-Term Care Insurance, those of the ADL-B are Care Level 4 and 3, and those of the ADL-C are Care Level 5 and 4 . There was a significant difference in the Care Level among ADL-A, B, and $C\left(\chi^{2}=145.4, \mathrm{p}<0.0001\right)[2]$.

We estimated the HSUVs of AD with CVD using the data of Kurimoto et al. [17], which is the HSUVs of the Long-Term Care Insurance. The HSUVs of the ADL-A in AD with CVD are Care Level $1+2 / 2=0.61+0.54 / 2=0.58$. The HSUVs of the ADL-B in AD with CVD are Care Level $3+4 / 2=0.45+0.11 / 2=0.28$. The HSUVs of the ADL-C in AD with CVD are Care Level $4+5 /$ $2=0.11-0.01 / 2=0.05$.

\section{Discussion}

From the results of the literature search, there has been no previous report on HSUVs associated with the level of physical activity of patients with AD with or without CVD. Using the previous reports and the mobility subscale of the EQ-5D, we estimated that the HSUVs of pure $\mathrm{AD}$ and $\mathrm{AD}$ with CVD for ADL levels A, B, and C were 0.61 and $0.58,0.53$ and 0.28 , and 0.19 and 0.05 , respectively. 


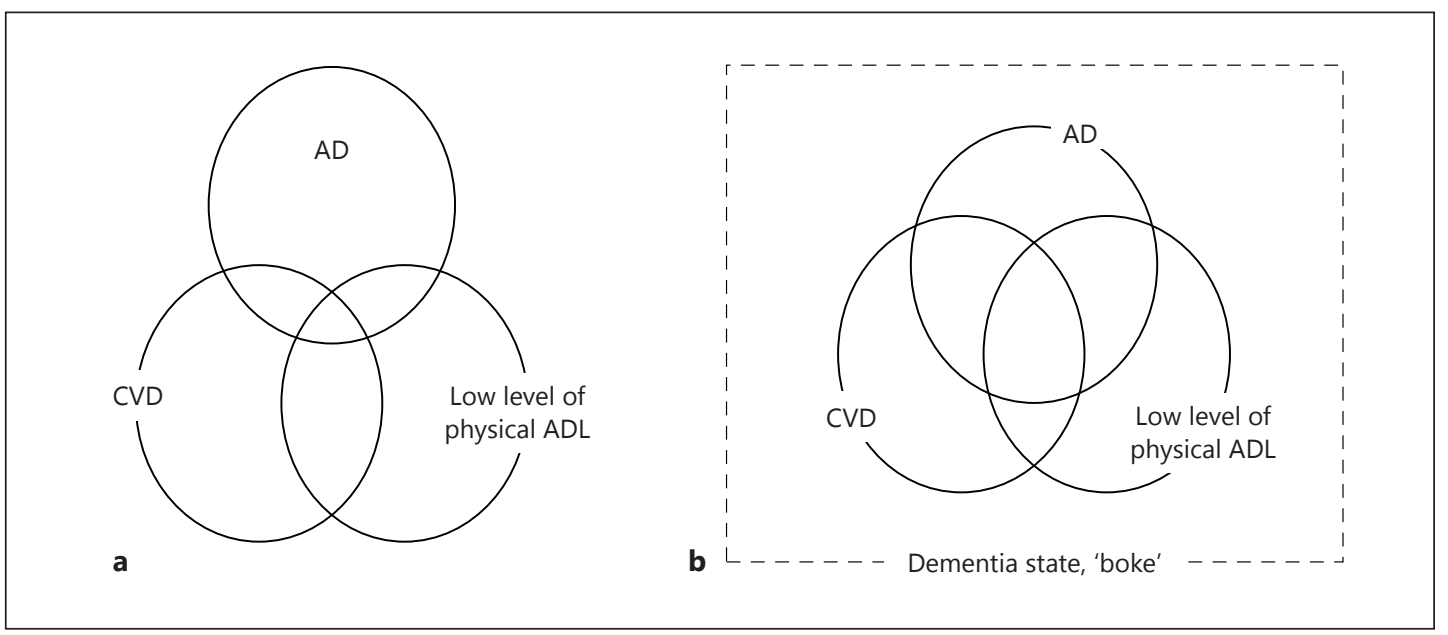

Fig. 2. The models of the relationship between $A D, C V D$, and a low level of physical ADL in Europe and the USA (a) and Japan (b).

HSUVs for AD when taking ADL into consideration were evaluated based on domestic and international studies. No international articles were found that estimated the HSUVs by the severity of $\mathrm{AD}$ and the extent of ADL. No studies have considered complications including CVD, but domestic studies on items of AD [16], long-term care [17], and the extent of ADL [18] were found. However, none of these articles evaluated all these issues together. An estimated HSUV value was calculated based on ADL. These results may be more accurate than previous estimations of the HSUVs. We suggest that the analysis of healthcare economics of dementia in Japan can be improved through consideration of the extent of ADL, in addition to the severity of AD.

Figure 2 shows our hypothesis of a concept of a dementia state. Figure $2 \mathrm{a}$ is a model of a concept of a dementia state in the EU and the USA. In the EU and the USA, comparatively few mild AD patients may have CVD and low levels of physical ADL. However, in Japan (fig. 2b), most mild AD patients may have CVD and low levels of physical ADL. This state is called 'boke' in Japanese.

Galantamine showed a good therapeutic effect on cognitive functions and ADL abilities in patients with AD combined with CVD as well as AD [19-21]. To perform more appropriate evaluation of the effectiveness of medication, we need to identify AD patients and AD with CVD patients and we need to take ADL capability into consideration.

In conclusion, more AD patients have CVD and low levels of physical ADL in Japan compared to $\mathrm{AD}$ patients in the EU and the USA. For health policy decision making about dementia, simply considering the direct effect of drug treatment on AD is not enough. Rather, the effect on ADL should be considered, especially in Japan.

\section{References}

1 Meguro K, Ishii H, Yamaguchi S, Ishizaki J, Shimada M, Sato M, Hashimoto R, Shimada Y, Meguro M, Yamadori A, Sekita Y: Prevalence of dementia and dementing diseases in Japan: the Tajiri Project. Arch Neurol 2002;59: 1109-1114.

-2 Meguro K, Tanaka N, Kasai M, Nakamura K, Ishikawa H, Nakatsuka M, Satoh M, Ouchi Y: Prevalence of dementia and dementing diseases in the old-old population in Japan: the Kurihara Project. Implications for Long-Term Care Insurance data. Psychogeriatrics 2012;12:226-234. 
3 Kasuya M, Meguro K: Health economic effect of donepezil treatment for CDR 0.5 converters to Alzheimer's disease as shown by the Markov model. Arch Gerontol Geriatr 2010;50:295-299.

4 Ikegami N, Fukuhara S, Ikeda S: QOL evaluation handbook for clinical diagnosis (in Japanese). Tokyo, Igaku Shoin, 2001, pp 45-49.

5 Japanese EuroQol Translation Team: The development of the Japanese EuroQol Instrument. J Health Care Soc 1998;8:109-123.

-6 Hurst NP, Jobanputra P, Hunter M, Lambert M, Lochhead A, Brown H: Validity of Euroqol - a generic health status instrument - in patients with rheumatoid arthritis. Economic and Health Outcomes Research Group. Br J Rheumatol 1994;33:655-662.

7 The EuroQol Group: EuroQol - a new facility for the measurement of health-related quality of life. Health Policy 1990;16:199-208.

8 Meguro K, Ueda M, Yamaguchi T, Sekita Y, Yamazaki H, Oikawa Y, Kikuchi Y, Matsuzawa T: Disturbance in daily sleep/wake patterns in patients with cognitive impairment and decreased daily activity. J Am Geriatr Soc 1990;38:1176-1182.

-9 Arai Y, Zarit SH, Kumamoto K, Takeda A: Are there inequities in the assessment of dementia under Japan's LTC insurance system? Int J Geriatr Psychiatry 2003;18:346-352.

10 Shearer J, Green C, Ritchie CW, Zajicek JP: Health state values for use in the economic evaluation of treatments for Alzheimer's disease. Drugs Aging 2012;29:31-43.

11 Jönsson L: Cost-effectiveness of memantine for moderate to severe Alzheimer's disease in Sweden. Am J Geriatr Pharmacother 2005;3:77-86.

12 Andersen CK, Wittrup-Jensen KU, Lolk A, Anderson K, Kragh-Sorensen P: Ability to perform activities of daily living is the main factor affecting quality of life in patients with dementia. Health Qual Life Outcomes 2004;2: 52.

13 Tengs TO, Lin TH: A meta-analysis of quality-of-life estimates for stroke. Pharmacoeconomics 2003;21:191200.

14 van der Gaag A, Brooks R: Economic aspects of a therapy and support service for people with long-term stroke and aphasia. Int J Lang Commun Disord 2008;43:233-244.

15 Johnson SJ, Diener MD, Kaltenboeck A, Birnbaum HG, Siderowf AD: An economic model of Parkinson's disease: implications for slowing progression in the United States. Mov Disord 2013;28:319-326.

16 Yasuda A, Kawano Y, Kinoshita T, Utsumi K, Okumura A, Shigenobu K: Changes in the comprehensive-healthrelated QOL of persons with dementia of the Alzheimer type (DAT) treated with donepezil and their primary carers (in Japanese). Jpn J Geriatr Psychiatr 2011;22:1433-1445.

17 Kurimori S, Fukuda Y, Hoshi T, Ota H: Measurement of utility for care levels in the revised Long-term Care Insurance System and calculation of prefectural weighted disability prevalence (WDP) and disability-adjusted life expectancy (DALE) (in Japanese). J Natl Inst Publ Health 2010;59:152-158.

18 lzumi R, Noto S, Uemura T, Sano T, Sato T: Validity and responsiveness of the health utility measures Japanese version in health related quality of life: evaluation of the use of EuroQol 5-Dimension and the Health Utilities lndex Mark 3 (in Japanese). J Jpn Assoc Occup Ther 2010;29:763-772.

19 Erkinjuntti T, Kurz A, Gauthier S, Bullock R, Lilienfeld S, Damaraju CV: Efficacy of galantamine in probable vascular dementia and Alzheimer's disease combined with cerebrovascular disease: a randomised trial. Lancet 2002;359:1283-1290.

20 Kurz AF, Erkinjuntti T, Small GW, Lilienfeld S, Damaraju CR: Long-term safety and cognitive effects of galantamine in the treatment of probable vascular dementia or Alzheimer's disease with cerebrovascular disease. Eur J Neurol 2003;10:633-640.

-21 Erkinjuntti T, Gauthier S, Bullock R, Kurz A, Hammond G, Schwalen S, Zhu Y, Brashear R: Galantamine treatment in Alzheimer's disease with cerebrovascular disease: responder analyses from a randomized, controlled trial (GAL-INT-6). J Psychopharmacol 2008;22:761-768. 